\title{
质子交换膜燃料电池的三维流场技术研究进展
}

\author{
周伟 朱金宁连云崧 游昌堂 \\ (厦门大学机电工程系 厦门 361005)
}

\begin{abstract}
摘要: 流场板是质子交换膜燃料电池的核心组件之一, 其流场结构直接影响着反应气体的传输分配以及燃料电池的排水与散 热性能。常规流场往往存在水分布不均和局部热点的现象, 容易导致燃料电池输出性能退化, 甚至造成系统崩溃。三维流场 具有优异的传质传热特性, 能有效提高质子交换膜燃料电池性能, 已成为当前研究热点。根据流场结构形式的不同, 三维流 场可分为复杂三维流场、销形三维流场、泡沫三维流场、集成三维流场、波浪三维流场和仿生三维流场等。通过介绍质子交 换膜燃料电池的三维流场工作原理, 重点分析了不同三维流场结构在水热管理方面的优势, 并进一步讨论了增强水热管理的 技术措施; 总结概述了三维流场结构的常用加工制造技术，详细分析了加工制造技术的优缺点; 最后归纳分析了三维流场在 实际应用中面临的挑战及未来的发展趋势。
\end{abstract}

关键词: 质子交换膜燃料电池; 三维流场; 水热管理

中图分类号: TM911

\section{Research Progress on Three-dimensional Flow Field Technology of Proton Exchange Membrane Fuel Cell}

\author{
ZHOU Wei ZHU Xinning LIAN Yunsong YOU Changtang \\ (Department of Mechanical \& Electrical Engineering, Xiamen University, Xiamen 361005)
}

\begin{abstract}
The flow field plate is one of the core components of the proton exchange membrane fuel cell (PEMFC), and its flow field structure directly affects the transmission and distribution of reactive gas and the drainage and heat dissipation performance of the fuel cell. The phenomenon of uneven water distribution and local hot spots are common in conventional flow fields, which will lead to degradation of fuel cell output performance and even breakdown of the system. The three-dimensional flow field has excellent mass and heat transfer performance, which can effectively improve the performance of proton exchange membrane fuel cell, and has become a research hotspot. According to the different structure of flow field, three-dimensional flow fields can be divided into complex three-dimensional flow field, pin-type three-dimensional flow field, foam three-dimensional flow field, integrated three-dimensional flow field, wave three-dimensional flow field, bionic three-dimensional flow field and so on. By introducing the working principle of the three-dimensional flow field of proton exchange membrane fuel cell, the advantages of a three-dimensional flow field structures in water and heat management are analyzed emphatically, and the technical measures to enhance the water and heat management are further discussed. At the same time, the common manufacturing technologies of three-dimensional flow field structure are summarized, and the advantages and disadvantages of manufacturing technology are analyzed in detail. Finally, the challenges in practical application and the future development trend of the three-dimensional flow field are summarized and analyzed. Key words: proton exchange membrane fuel cell; three-dimensional flow field; water and heat management
\end{abstract}

\section{0 前言}

质子交换膜燃料电池具有启动温度低, 零排放, 能量转换效率高, 能量密度大等突出优点, 且不受

\footnotetext{
* 国家自然科学基金优秀青年科学基金(51922092)和中央高校基本科研业 务费专项资金(20720200068)资助项目。20200805 收到初稿, 20210315 收到修改稿
}

卡诺循环限制, 被认为是未来交通运载工具动力输 出系统的必然选择。双极板是质子交换膜燃料电池 重要的组成部分, 具有传导电子, 分配气体的作用。 双极板上制成的流场可以引导反应气体渗透气体扩 散层，并对生成的水热进行管理。

根据流场结构特性的不同, 流场可分为常规流 场和三维流场 ${ }^{[1-2]}$ 。常规流场结构简单, 气体流向单 一; 三维流场结构复杂立体, 气体流向三线交叉, 
具有明显空间效应。与常规流场相比, 三维流场具 有较强的对流效应, 能将催化层与扩散层中的水吸 出并进行气液分离, 以降低水积累对燃料电池性能 影响。此外, 三维流场的交叉流动方式改善了反应 气体分布的均匀性, 实现了反应热的均匀分布, 解 决了燃料电池热管理问题, 提高了燃料电池的输出 性能。因此, 三维流场具有突出的水热管理功能, 是未来技术发展的主流方向。

在近年研究工作中, 众多科研工作者研发了多 种新型三维流场, 并不断优化提升水热管理性能, 以期提高燃料电池输出性能。值得注意的是, 丰田 公司研制出 3D 微晶格结构的复杂三维流场, 并成 功应用在丰田 Mirai 燃料电池车中, 且已实现商业 化 ${ }^{[3-4]}$ 。本文从三维流场出发, 详细介绍了流场工作 原理, 重点分析了三维流场在水热管理方面的优势, 全面阐述了不同三维流场结构的加工技术, 总结归 纳了三维流场实际应用中所面临的挑战, 以期为三 维流场水热管理性能的深入研究提供理论指导。

\section{1 三维流场工作原理}

质子交换膜燃料电池主要由双极板、气体扩散 层(Gas diffusion layer, GDL) 、催化层(Catalytic layer, $\mathrm{CL}$ )、质子交换膜(Proton exchange membrane, PEM) 几个重要部分组成。图 1 为电堆结构模型图。根据 流场结构的不同, 三维流场可分为复杂三维流场、 销形三维流场、泡沫三维流场、集成三维流场、波 浪三维流场和仿生三维流场。

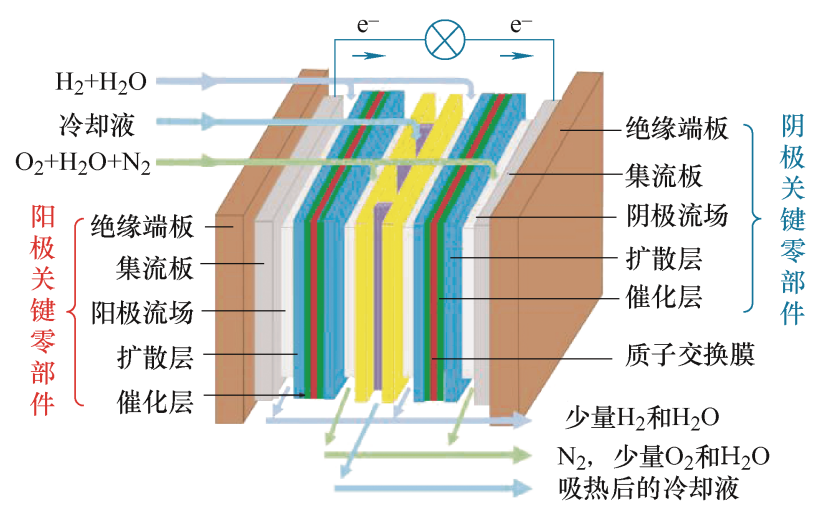

图 1 电堆结构模型图

质子交换膜燃料通过阳极燃料 $\left(\mathrm{H}_{2}\right)$ 电化学氧化 和阴极氧化剂 $\left(\mathrm{O}_{2}\right)$ 电化学还原直接产生电流。燃料 电池工作时, 反应气体在三维流场导流作用下到达 发生化学反应的催化层。在催化层中, 反应气体被 催化剂吸附并发生电催化反应, 生成质子和电子。 生成的质子从阳极侧穿过质子交换膜达到电池阴
极, 电子通过对外做功的方式到达阴极。在阴极侧 催化剂作用下, 氧气、质子与电子发生反应生成水, 并释放大量的热量。电极反应方程式如下所示 ${ }^{[5-6]}$

阳极: $2 \mathrm{H}_{2} \rightarrow 4 \mathrm{H}^{+}+4 \mathrm{e}^{-}$

阴极: $\mathrm{O}_{2}+4 \mathrm{e}^{-}+4 \mathrm{H}^{+} \rightarrow 2 \mathrm{H}_{2} \mathrm{O}$

电池反应: $\mathrm{H}_{2}+1 / 2 \mathrm{O}_{2} \rightarrow \mathrm{H}_{2} \mathrm{O}+Q$ (热量)

\section{2 三维流场水管理研究}

\section{1 复杂三维流场}

最近, 复杂三维流场设计已引起了人们广泛的关 注。图 $2^{[7-8]}$ 为复杂三维流场结构图, 与常规流场不同, 复杂三维流场中氧气与氢气呈垂直状流动, 且气体扩 散层与阴极流场之间存在较为频繁的微尺度界面通 量, 在特殊的流动状态与重复微尺度对流的协同作用 下, 质子交换膜燃料电池传质与除水能力得到提升 ${ }^{[7]}$ 。
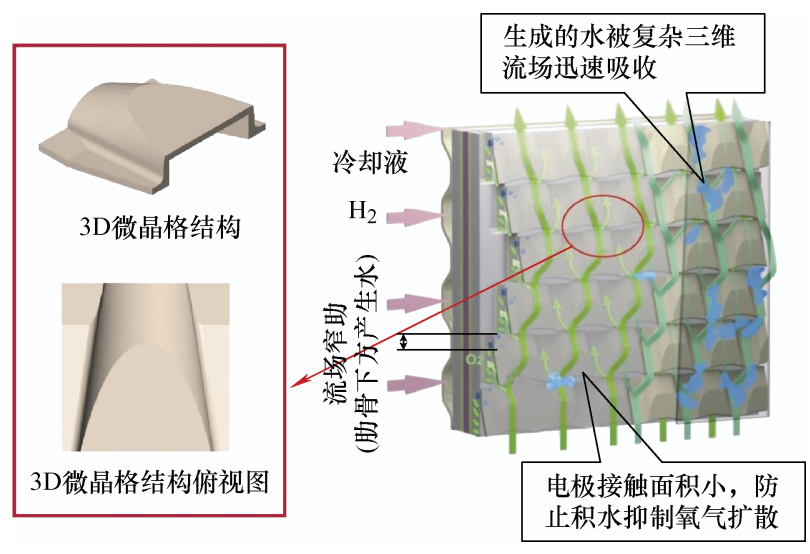

图 2 复杂三维流场结构图

由于 $3 \mathrm{D}$ 微晶格结构的存在, 福希海默效应广 泛存在于复杂三维流场中, 且处于主导地位 ${ }^{[9-10]}$ 。 如图 3 所示 ${ }^{[9]}$, 福希海默效应能增大流道与扩散层 界面处的质量通量 ${ }^{[11]}$, 并将催化层与扩散层的水吸 附到流道。在 $3 \mathrm{D}$ 微晶格结构中, 气液进行分离 ${ }^{[12]}$, 液态水被排出。通过调整 $3 \mathrm{D}$ 微晶格排列方式以增

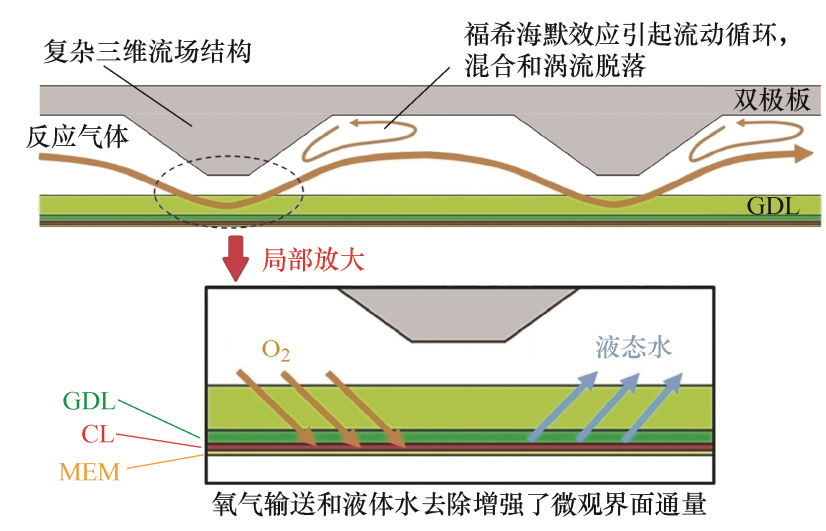

图 3 复杂三维流场传质过程 
强福希海默效应, 不仅降低了流道与气体扩散层的 水饱和度, 而且还增加了扩散层反应气体通量, 从 而使燃料电池性能得到提升。

\section{2 销形三维流场}

具有梯度块结构的流场为销形三维流场。如 图 4 所示 ${ }^{[13-15]}$ 。销形三维流场的梯度块形状呈多样化, 包括正方形、菱形和六边形。梯度块结构能起到分流 和导流作用, 从而提高了流场传质能力。梯度块结构 的锐角由默里定律确定 ${ }^{[16]}$, 能影响销形三维流场的速 度分布规律。与常规流场不同, 销形三维流场梯度块 结构背面出现两个速度顶点, 具有增强传质和排水的 功能。根据液态水生长规律, 销形三维流场水滴过程 可分为水出现、生长、变形和脱离 ${ }^{[17]}$ 。

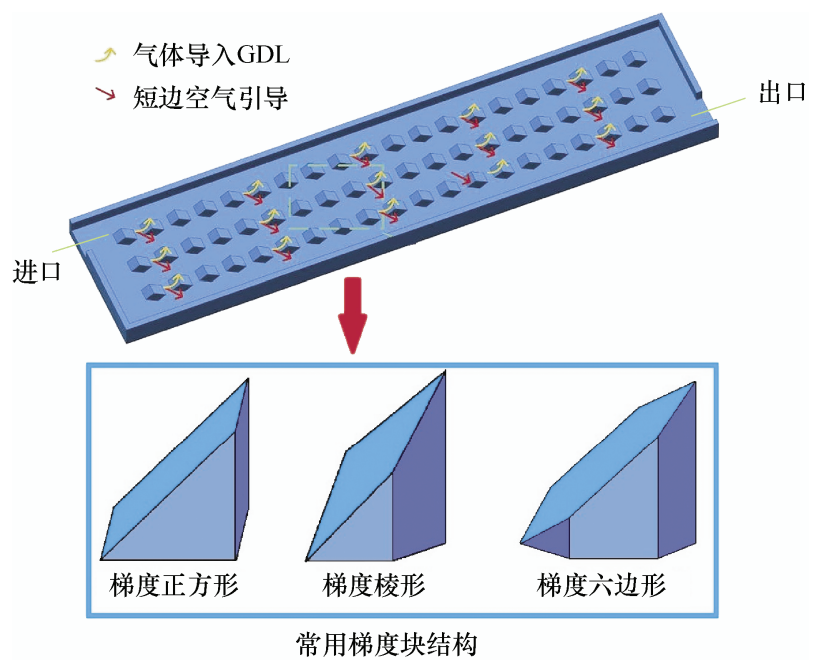

图 4 销形三维流场结构图

深入研究梯度块结构发现, 当单位长度内梯度 块结构的排列密度增大时, 流场的流动面积逐渐减 小, 导致销形三维流场输水性能不断降低。继续研 究发现, 梯度块结构倾斜角减小时, 销形三维流场 的排水效率逐渐增大。梯度块结构倾斜角较大的销 形三维流场适合在相对湿度低, 化学计量比高和工 作压力小的条件下工作 ${ }^{[18]}$ 。进一步研究发现, 增加 梯度块结构高度会提高流场的堵塞效果, 从而增加 了销形三维流场的排水效率, 进而避免阴极生成液 泛区域 ${ }^{[19]}$ 。CHEN 等 ${ }^{[10]}$ 研究了气体流速和接触角对 PEMFC 排水性能的影响。研究结果发现, 提高气体 流速时, 销形三维流场中液滴的生长速度逐渐减小, 相应的排水效率不断增大。继续深入研究发现, 当 接触角逐渐减小时, 销形三维流场中形成的液滴体 积相应增大, 从而导致液滴表面张力不断增大, 相 应的排水效率逐渐降低。

\section{3 泡沫三维流场}

多孔泡沫由于具有孔隙率高、表面积大等优异的
物理性能, 被用于替代燃料电池中的常规阴极流 道 ${ }^{[20]}$ 。根据材料的不同 ${ }^{[21-24]}$, 多孔泡沫材料可以分为 两大类: 多孔金属泡沫和石墨烯泡沫。如图 5 所示 ${ }^{[25]}$, 与常规流场相比, 泡沫三维流场表现出优异的排水性 能，不仅水分布均匀，而且排水效率更高 ${ }^{[25]}$ 。
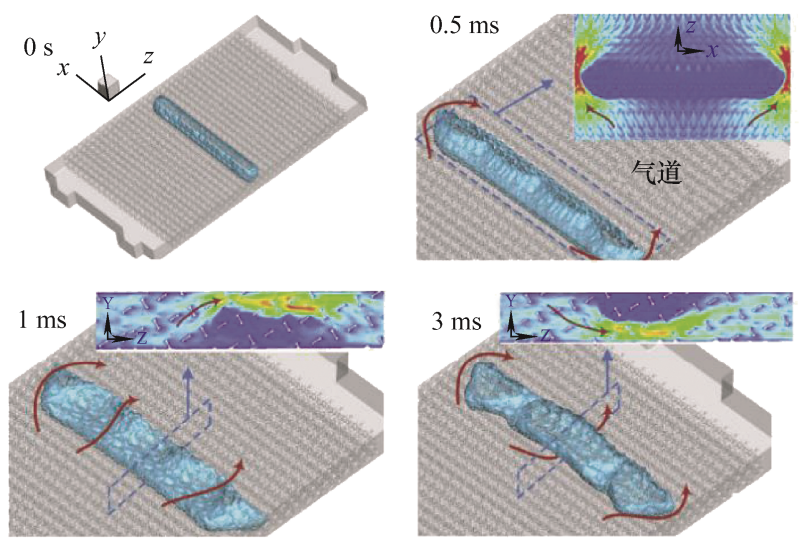

图 5 泡沫三维流场排水情况

与常规流场相比, 泡沫三维流场表现出更低的 水饱和度和更好的均匀性。在相同的工况条件下, 泡沫三维流场的水饱和度均低于常规流场 ${ }^{[26]}$ 。适当 地增加气体流速和流量化学计量比, 能有效提高泡 沫三维流场的排水效率。值得注意的是, 除了高 效除水性能, 泡沫三维流场还具有加湿器的功能。 图 $6^{[27]}$ 为常规流场与泡沫三维流场水分布情况。如 图 6 所示, 与常规流场相比, 泡沫三维流场均匀加 湿能力更强。在高温低流量工况下, 两极流道均为 泡沫三维流场的加湿性能最好 ${ }^{[27]}$, 此外, 两极泡沫三 维流场采用逆流方式还能提高水蒸气传递速率。适当 扩宽流场宽度与深度, 增加进气流量, 降低进气温度, 泡沫三维流场的保湿性能将得到进一步提升。

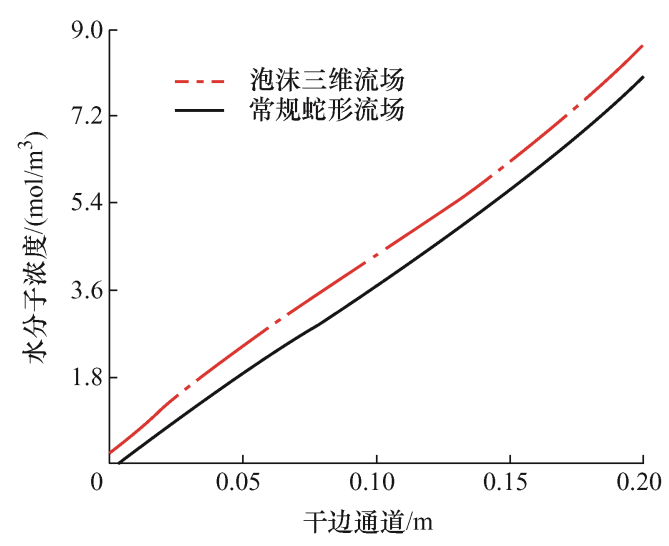

图 6 常规与泡沫三维流场对水分布的影响

\section{4 波浪三维流场}

波浪三维流场是一种新型流场结构, 具有特殊 的周期几何特性 ${ }^{[28]}$ 。周期性流场结构存在局部涡旋 现象, 能有效强化气体的径向流动, 从而降低氧浓 
度损失 ${ }^{[29]}$ 。周期性的波浪状结构能使局部流动方 向、局部流速和局部压力发生周期性变化, 提高了 燃料电池强制对流的性能, 增强了波浪三维流场的 排水性能 ${ }^{[30]}$ 。值得注意的是, 波浪结构的间隙越小, 波浪三维流场的排水性能越显著 ${ }^{[31]}$ 。由图 $7^{[32]}$ 可知, 与常规流场相比, 波浪三维流场具有较高的排水特 性。随着最小孔道深度和波浪波长的减小, 波浪三维 流场的排水性能得到显著提高 ${ }^{[32]}$ 。为了更进一步提高 波浪三维流场排水性能, YAN 等 ${ }^{[33]}$ 设计了梯度波浪三 维流场。研究结果表明, 与常规波浪三维流场相比, 梯度波浪三维流场能有效增加气流速度, 增强局部 气流浴旋, 进一步提高了流场的排水性能。

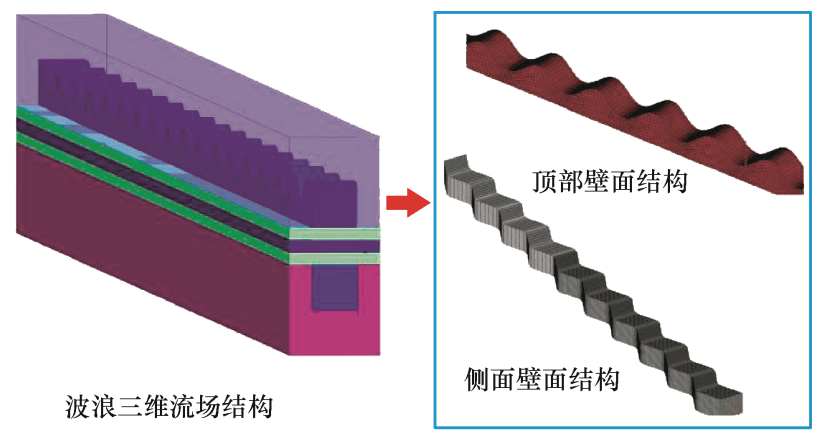

图 7 波浪三维流场结构图

由于波浪通道内存在剪切力和压力, 生成的液 滴不断提升并接触到通道侧壁和顶壁。水在壁面上 经历液滴生长, 液滴分离, 液滴提升, 水膜在壁面 上扩散 4 个阶段。为提高波浪三维流场通道壁面的 排水性能, ANYANWU 等 ${ }^{[34]}$ 研究了不同条件下波浪 通道壁面上水的流动规律, 如图 8 所示。研究结果 表明, 壁的接触角极大地影响水滴运输, 破裂以及粘 附壁面的时间。继续深入研究发现, 采用略带亲水性 的基底将有助于扩散层表面液滴的完全去除, 而选取 具有疏水性的壁面能更快地去除壁面粘附的液滴。

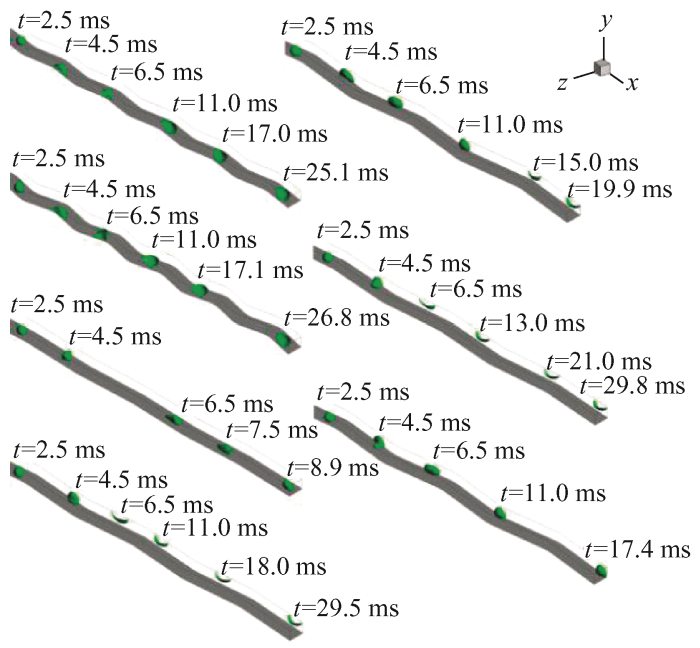

图 8 波浪通道排水特性

\section{5 新型三维流场}

FAN 等 ${ }^{[35]}$ 设计了新型的三维流场结构, 并深入 研究其排水性能。图 $9^{[35]}$ 为由多板结构通道组成的 新型三维流场。可以清晰观察到, 多板结构通道由 导风板，侧导液板和中间导液板组成。导风板可以 引导反应气体均匀渗透扩散并达到发生反应的催化 层。侧/中导液板具有液体导流功能, 通过分级方式 引导流场液态水的排出。此外, 通过侧导液板与导 风板距离合理的设计, 有效提高了流场的排水性能。

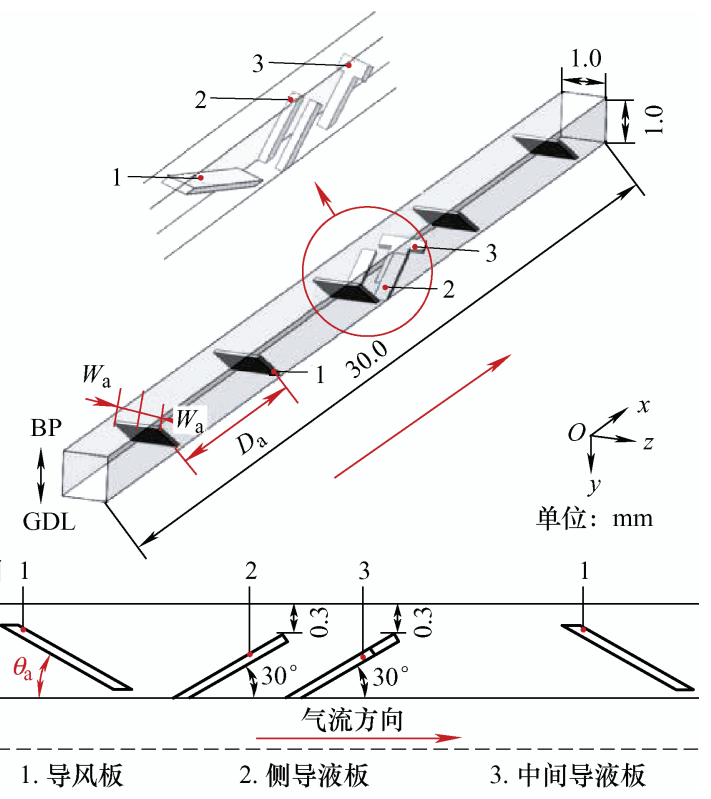

图 9 具有多板结构通道的新型三维流场

图 $10^{[35]}$ 为由集成结构通道组成的新型三维流 场。集成结构通道由辅助导风板、导风块、侧导液

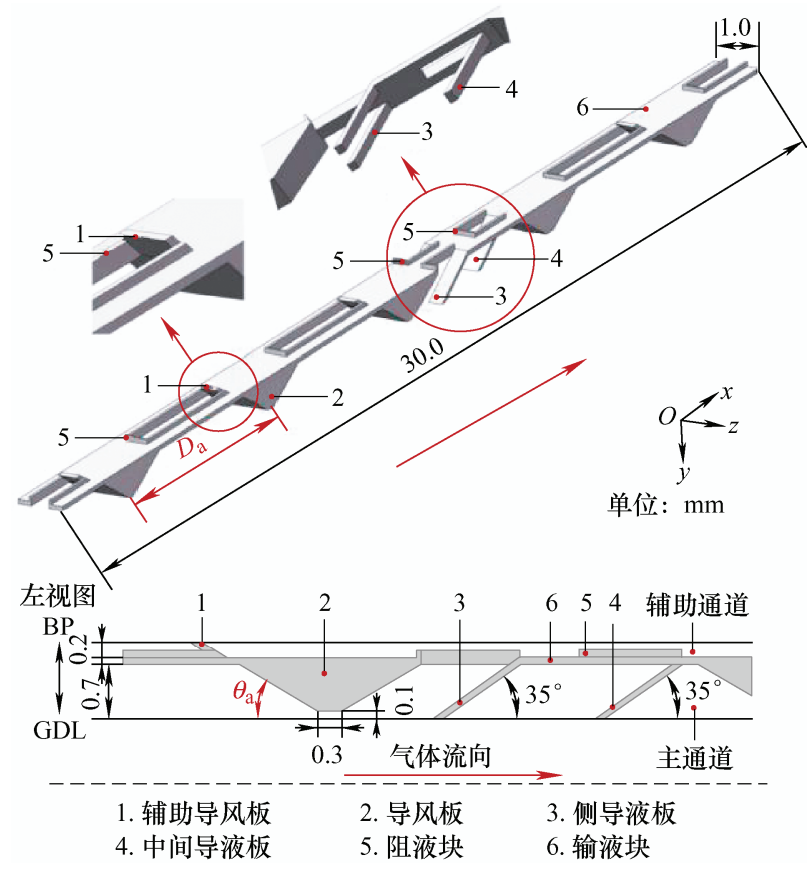

图 10 具有集成结构通道的新型三维流场 
板、中间导液板、阻液块和输液板组成。与多板结 构不同, 集成结构通道分为主通道和辅助通道。在 辅助导风板作用下, 辅助通道中反应物被引导至主 通道, 经过导流块向催化层渗透。侧/中导液板具有 气液分离功能, 将液态水引导至辅助通道。

\section{3 三维流场热管理研究}

\section{1 三维流场热管理效果}

三维流场流速均匀, 对流效果好、具有良好的 传质传热能力。流场结构是三维流场诸多优良特性 的物理基础 ${ }^{[36-37]}$ 。合理的流场结构设计, 巧妙地强 化了反应气体的径向流动效果, 提高了三维流场与 气体扩散层之间的微尺度界面反应气体分布均匀性 以及温度均匀度, 此外, 三维流场结构中流体交替 流动, 不仅提高了流场传质能力, 而且改善了三维 流场热边界条件, 同时降低了温度波动幅度。

图 $11^{[7-8,18,27,32,38]}$ 为不同三维流场结构图。按 照燃料电池热特性的要求, 众多科研工作者根据特 殊的流场构造, 制成了多种新型三维流场。以多孔 泡沫作为流道的泡沫三维流场, 提高了反应物分布
均匀性以及微尺寸界面温度均匀度, 降低了工作温 度振幅, 保证了燃料电池性能输出的稳定性。3D微 晶格作为复杂三维流场的流道结构, 呈轴向并列, 纵 向略微交错的方式分布。3D 微晶格特殊性布置, 强 化了流体径向流动, 提高了反应物和温度分布的均 匀性, 降低了流场热边界层厚度, 提高了热管理能 力。仿生三维流场流道结构曲折, 具有明显空间效 应。受生物脉络结构启发制成的仿生三维流场能有 效提高反应物分布的均匀性, 并以恒温的方式保证 反应的有序进行。周期性波浪流道具有导流功能, 诱导三维流场发生二次流现象。波浪三维流场特殊的 周期性结构, 不仅增强了气体分布的均匀性, 而且还 提高了流场气体的对流强度, 甚至解决了燃料电池局 部热点问题。利用多板具有的分流功能, 巧妙地设计 出新型三维流场流道结构。新型三维流场多板结构的 纵向布置, 增加了流场上端流体的雷诺系数, 保证了 流场下端温度分布的均匀性。销形三维流场块结构具 有一定的梯度, 对流体起导流作用。销形三维流场梯 度块结构的特殊设计, 提高了反应物分布的均匀性, 此外, 块结构厚度的合理设计, 增加了流场的比表面 积, 进而保证燃料电池性能的输出。

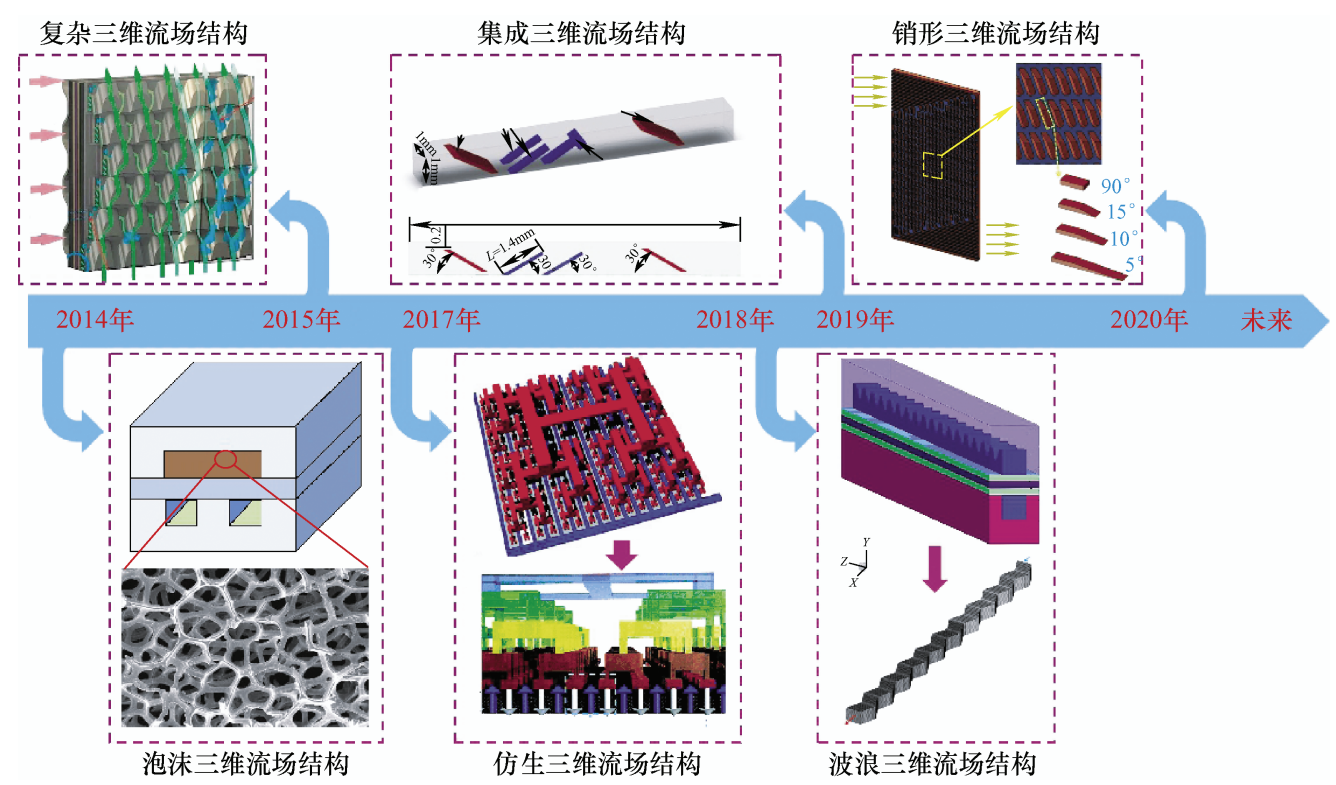

图 11 不同三维流场结构图

\section{2 增强三维流场热管理的技术方法}

除了三维流场结构设计, 材料应用 ${ }^{[39-40]}$ 和工况优 化 ${ }^{[41-43]}$ 对三维流场热管理性能也产生一定的影响。

\subsection{1 材料的应用}

材料物性对改善三维流场热边界条件具有至关 重要的影响。燃料电池采用高导热率金属材料, 增 加了流场散热效率, 降低了运载过程中的温度梯度, 提高了工作温度稳定性, 增强了燃料电池热管理性
能。此外, 采用一定刚度和韧性的材料, 不但降低 了燃料电池的厚度, 而且还提高了机械强度, 同时 也节约制造和时间成本，提高经济效益。

图 12 为三维流场常用材料 SEM 图。石墨烯和 镍为泡沫三维流场多孔结构常用材料, 具有良好的 韧性。以石墨烯材料制成的非金属多孔结构，增强 了反应气体均匀渗透能力, 保证了反应过程温度均 匀性。金属镍多孔结构不但具有非金属多孔结构的 
优点, 而且还可以利用金属优良的导热特性实现三 维流场温度控制, 即降低了燃料电池运载时的温度 振幅, 也保证了最佳工作温度区间。铝和铜为三维 流场边缘冷却系统常用材料, 具有较高的导热率和 机械强度。以铝和铜为材料的散热器和热管通过合 理设计, 不仅满足了大功率燃料电池边缘冷却要求, 而且还实现了三维流场的温度控制, 同时解决了燃 料电池在高电流工作条件下无法及时散热的问题。 亚克力材料具有透明度高, 导热性差的特点, 仅适 用于需可视化热成像的小功率燃料电池。金具有良 好的导热导电特性, 常被作为三维流场边缘涂敷材 料。边缘涂敷金的三维流场, 不仅避免了局部热点 现象发生, 而且还保证了燃料电池良好的输出性能。

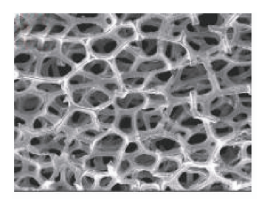

镍

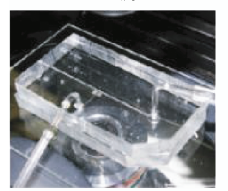

玻璃

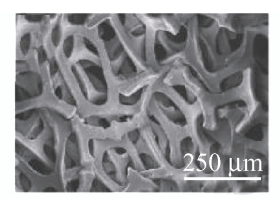

石墨烯

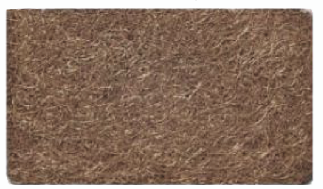

铜

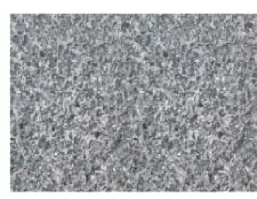

铝

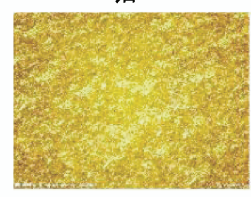

金
图 12 三维流场常用材料

\subsection{2 工况参数的优化}

工况参数的优化通常是指通过调整进气速率, 加湿温度, 压力及其他参数, 以保证三维流场气体 分布的均匀性, 提高温度分布的均匀性, 降低温度 振幅, 并使工作温度维持在最佳温度范围内, 从而 提高电池输出功率。

在进气速率方面, 当流场的进气速率较小时, 三维流场内反应物分布较均匀, 温度均匀分布且 振幅较小, 此时的电池无热故障问题; 当进气速 率逐渐增大时, 流场内温度均匀度降低, 振幅相 应增大, 但其温度仍然处于最佳工作范围内, 此 时, 电池无明显的热故障问题, 且输出性能得到 提升; 随着进气速率进一步增大, 较高的流速导 致反应气体驻留时间减小, 流场内温度梯度增大。 此时, 采用以强制对流为导热机制的热管理措施 效果不明显, 且难以使三维流场的工作温度控制 在最佳范围内, 燃料电池输出性能逐渐降低。因 此, 适当的提高进气流速有利于三维流场性能的 增强, 过高的进气流速会导致三维流场面临温度 难以控制、气体分布不均匀等问题。进气压力的 增加导致流场压差相应增大, 促使流场内流速不 断增大。因此, 压力对三维流场性能的影响机理
与进气速率是一致的 ${ }^{[44-45]}$ 。

在反应气体加湿温度方面, 当加湿温度高于三 维流场工作温度时, 大量水蒸气冷凝并积累在三维 流场中，水积累现象导致三维流场气体分布均匀性 不断降低。当加湿温度等于三维流场工作温度时, 避免了反应气体中水蒸气相变的发生, 此时的三维 流场气体分布逐渐变得均匀; 当加湿温度小于三维 流场工作温度时, 化学反应生成的水吸热汽化, 流 场内水积累量逐渐减小, 气体分布均匀性进一步增 大，从而有效降低了热故障发生的概率。

\section{4 三维流场的制造技术}

\section{1 发泡技术}

发泡技术是指通过物理发泡或化学交联发泡方 式使材料发泡(开孔或闭孔型)具有轻量、吸音、吸 震、保温、过滤等功能的技术。以超临界流体为发 泡剂的发泡技术不仅绿色环保、造价低, 而且制备 的多孔结构可控、性能优异。通过发泡技术制成的 开孔型泡沫结构不仅具有较强的水吸收率, 而且还 具有较高的气体渗透率, 同时还具有较高的导热导 电率。

余鹏等 ${ }^{[46]}$ 对超临界流体发泡技术进行了全面 综述。研究发现, 通过发泡技术制成的三维互通 泡沫结构具有优异的吸收和渗透性能。王小峰 等 ${ }^{[47]}$ 利用物理化学联合发泡技术制出了具有 “网” 状结构的泡沫，改善了发泡制品的开孔性。 SANTOS 等 ${ }^{[48]}$ 研究发现通过超临界流体发泡技 术制备的微孔三维立体结构无泡孔塌陷现象, 开 孔率较好, 孔壁平滑。

\section{2 液压成形技术}

液压成形技术是以液体为传力介质或模具的一 种金属塑性成形的加工技术。通过液压成形技术制 造的零部件不仅具有较高的表面质量和尺寸精度, 而且还具有较低的生产周期和制造成本。 MAHABUNPHACHAI 等 ${ }^{[49]}$ 通过试验对比并分析了 冲压和液压成形工艺对双极板表面粗粘度的影响。 研究结果表明, 与冲压成形技术相比, 通过液压成 形技术制造的双极板尺寸误差减小了 $17 \%$ ，且表面 粗糙度显著降低。OSIA 等 ${ }^{[50]}$ 提出了冲压与液压相 结合的新颖液压成形工艺, 提高了成形轮廓尺寸 精度。

\section{3 激光加工}

激光加工技术是利用激光束能量对工件材料进 行切割、焊接、表面处理、打孔及微细加工的一种 
技术 ${ }^{[51]}$ 。激光加工作为先进制造技术, 具有加工精 度高、热效应小、可控性强等优势, 满足了汽车、 电子、航空、机械制造等领域的加工要求。通过激 光加工技术对新型三维流场导风板进行焊接, 提高 了导风板表面质量, 减小了材料消耗, 达到了节能 环保的目的。飞秒激光技术具有加工材料广、无接 触加工、脉冲宽度短、峰值功率高等优点, 常被用 于在粗糙表面制备超疏水表面。通过飞秒激光加工 技术, 不仅能实现复杂三维流场 3D 微晶格体超疏 水表面的制备, 而且还能对仿生三维流场微小脉络 结构通道进行加工。

\section{4 增材制造技术}

增材制造技术是运用粉末状金属或塑料等可粘 合材料, 通过逐层堆叠累积方式来构造物体的技

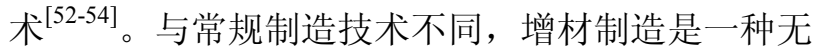
需模具快速成形的技术, 具有刚度高、动态性能好、 耗材少等优点, 常被用于制造关键零部件。利用增 材制造技术形成的 3D 微晶格, 不仅满足了结构紧 凑性要求, 而且还满足了零部件刚度的要求, 同时 还提高了尺寸精度和降低了表面粗粘度。通过增材 制造技术加工新型三维流场多板结构, 不仅降低了 材料的损耗，而且还降低了加工成本。

\section{5 铁削加工技术}

铣削加工是通过铣床上高速旋转的多刀铣刀, 对工件进行切削加工的方法 ${ }^{[55-56]}$ 。铣削加工的特点: (1) 断续切削; (2) 多刀多刃切削, 生产率高; (3) 可 选用不同铣削方式和刀具加工同一表面。采用数控 铁削加工技术不仅提高了零部件尺寸精度, 而且还 提高了生产率, 保证了零部件的大批量生产。周伟 等 ${ }^{[57]}$ 提出一种利用填充材料进行泡沫金属固化后 再进行孔结构保形铣削加工的新方法。研究结果表 明, 以孔结构保形铣削技术加工的泡沫金属孔径保 形率高达 $96.4 \%$ ，嵴保形率高达 $93.7 \%$ 。

\section{6 复合加工技术}

复合加工是指用多种加工组合进行材料去除的 工艺方法, 具有加工效率高、形状尺寸精度高和表 面完整性好等优点 ${ }^{[58-60]}$ 。三维流场结构常用的复合 加工技术有切削复合加工技术、电解电火花磨削加 工技术和增减材复合加工技术。

切削复合加工技术是激光与切削组合的一种加 工技术。通过激光束能量对工件局部瞬时加热, 降 低切削区材料强度, 提高其塑性, 进而增强切削加 工性能。切削复合加工技术优点: 切削速度高, 切 削效果好, 精度高, 可控性好; 电解电火花磨削加 工技术是利用电解腐蚀与机械磨削作用相结合的一
种新型磨削工艺。在电解电火花磨削加工技术中, 电解腐蚀与刮除薄膜的磨削方式交替进行, 使工件 加工精度得到提高, 表面粗粘度降低。增减材复合 加工技术是将结构设计、软件控制以及增材制造与 减材制造相结合的一种新加工技术, 具有准确度高、 精密度高、表面粗䊁度低、加工性能好、可控性强 和制造成本低等优点。

\section{5 三维流场当前存在问题}

虽然三维流场具有突出的水热管理性能, 但是 仍然无法满足极端环境下水热管理要求。因此, 三 维流场的未来发展方向更偏向于以下方面。

(1) 基于极端天气启动的研究。在极寒条件下, 三维流场的流道发生冰冻现象，导致燃料电池无法 正常启动, 如何快速去冰并缩短冷启动时间是其在 实际应用方面的一大难题。

（2）基于热响应时间的研究。热响应时间是验 证热管理技术有效性的重要因素。现有的文献对燃 料电池热响应时间的研究较少, 更是未见系统地研 究热响应时间对水热管理效果的影响规律。因此, 设计并优化热响应系统是未来水热管理技术的发展 趋势。

（3）基于余热利用效率的研究。由于燃料电池 结构的特殊性, 余热回收系统和热电联产系统的效 率较低, 从而使燃料电池运行成本增大。目前关于 燃料电池余热高效利用的研究相对较少, 未来具有 进一步研究的空间。

\section{6 结论与展望}

质子交换膜燃料电池具有启动温度低、零排放、 能量转换效率高等优点, 被认为是替代传统内燃机 最有前途的绿色能源转换装置, 已成为汽车、无人 机、海上应用的有用电源。流场板是质子交换膜燃 料电池的核心组件之一, 其流场结构直接影响着反 应气体的传输分配以及燃料电池的排水散热性能。 根据现有的文献报道分析，通过发泡技术、液压成 形技术、激光加工技术、增材制造技术、铣削加工 技术和复合加工技术研制的三维流场主要有复杂三 维流场、销形三维流场、泡沫三维流场、集成三维 流场、波浪三维流场和仿生三维流场等, 且已在燃 料电池反应气体分配和水热管理领域发挥着重要的 作用, 并取得了较好的研究成果, 同时也面临着重 大挑战。随着微纳制造技术和材料科学的快速发展, 
有关三维流场水热管理机理也得到更为深入的研 究, 相信在未来几年内必将会利用先进的制造加工 技术研制出更多的三维流场结构, 实现燃料电池水 热精细化管理, 推动质子交换膜燃料电池商业化发 展, 同时也为三维流场进一步研究提供理论基础和 参考价值。

\section{参 考 文 献}

[1] HUANG Z Y, SHEN J, CHAN S H, et al. Transient response of performance in a proton exchange membrane fuel cell under dynamic loading[J]. Energy Conversion and Management, 2020, 226: 113492.

[2] BAO Z M, NIU Z Q, JIAO K. Gas distribution and droplet removal of metal foam flow field for proton exchange membrane fuel cells[J]. Applied Energy, 2020, 280: 116011.

[3] NONOBE Y. Development of the fuel cell vehicle mirai[J]. IEEJ Transactions on Electrical and Electronic Engineering, 2017, 12(1): 5-9.

[4] YOSHIDA T, KOJIMA K. Toyota MIRAI fuel cell vehicle and progress toward a future hydrogen society[J]. The Electochemical Society Interface, 2015，24: 45-49.

[5] WILBERFORCE T, EI-HASSAN Z, KHATIB F N, et al. Developments of electric cars and fuel cell hydrogen electric cars[J]. International Journal of Hydrogen Energy, 2017, 42(40): 25695-25734.

[6] BARGAL M, ABDELKAREEM M, TAO Q, et al. Liquid cooling techniques in proton exchange membrane fuel cell stacks: A detailed survey[J]. Alexandria Engineering Journal, 2020, 59: 635-655.

[7] KONNO N, MIZUNO S, NAKAJI H, et al. Development of compact and high-performance fuel cell stack[J]. SAE International Journal of Alternative Powertrains, 2015, 4(1): 123-129.

[8] NIU Z Q, FAN L H, BAO Z M, et al. Numerical investigation of innovative 3D cathode flow channel in proton exchange membrane fuel cell[J]. International Journal of Energy Research, 2018，42: 3328-3338.

[9] KIM J Y, LUO G, WANG C Y. Modeling two-phase flow in three-dimensional complex flow-fields of proton exchange membrane fuel cells[J]. Journal of Power Sources, 2017, 365: 419-429.

[10] CHEN H, GUO H, YE F, et al. Modification of the two-fluid model and experimental study of proton exchange membrane fuel cells with baffled flow
channels[J]. Energy Conversion and Management, 2019, 195: 972-988.

[11] YOSHIDA T, KOJIMA K. Toyota MIRAI fuel cell vehicle and progress toward a future hydrogen society[J]. The Electochemical Society Interface, 2015，24: 45-49.

[12] HEIDARY H, KERMANI M J, DABIR B. Influences of bipolar plate channel blockages on PEM fuel cell performances[J]. Energy Conversion and Management, 2016, 124: 51-60.

[13] WEN D H, YIN L Z, PIAO Z Y, et al. A novel intersectant flow field of metal bipolar plate for proton exchange membrane fuel cell[J]. International Journal of Energy Research, 2017, 41: 2184-2193.

[14] ZHU X, SUI P C, DJILALI N. Three-dimensional numerical simulations of water droplet dynamics in a PEMFC gas channel[J]. Journal of Power Sources, 2008, 181: 101-115.

[15] ATYABI S A , AFSHARI E. Three-dimensional multiphase model of proton exchange membrane fuel cell with honeycomb flow field at the cathode side[J]. Journal of Cleaner Production, 2019, 214: 738-748.

[16] WANG B W, CHEN W M, PAN F W, et al. A dot matrix and sloping baffle cathode flow field of proton exchange membrane fuel cell[J]. Journal of Power Sources, 2019, 434: 226741.

[17] GUO N N, LEU M C, KOYLU U O. Network based optimization model for pin-type flow field of polymer electrolyte membrane fuel cell[J]. International Journal of Hydrogen Energy, 2013， 38: 6750-6761.

[18] HE L, HOU M, GAO Y Y, et al. A novel three-dimensional flow field design and experimental research for proton exchange membrane fuel cells[J]. Energy Conversion and Management, 2020, 205: 112335.

[19] PERNG S W, WU H W. A three-dimensional numerical investigation of trapezoid baffles effect on non-isothermal reactant transport and cell net power in a PEMFC[J]. Applied Energy, 2015, 143: 81-95.

[20] YUAN W, TANG Y, YANG X J, et al. Porous metal materials for polymer electrolyte membrane fuel cells: A review[J]. Applied Energy, 2010，94: 309-329.

[21] LI S, SUNDEN B. Three-dimensional modeling and investigation of high temperature proton exchange membrane fuel cells with metal foams as flow distributor[J]. International Journal of Hydrogen Energy, 2017, 42: 27323-27333. 
[22] LIU R L, ZHOU W, LI S L, et al. Performance improvement of proton exchange membrane fuel cells with compressed nickel foam as flow field structure[J]. International Journal of Hydrogen Energy, 2020, 45: 17833-17843.

[23] HUO S, COOPER N J, SMITH T L, et al. Experimental investigation on PEM fuel cell cold start behavior containing porous metal foam as cathode flow distributor[J]. Applied Energy, 2017, 203: 101-114.

[24] TILIAKOSA A, TREFILOV A M, TANASA E, et al. Laser-induced graphene as the microporous layer in proton exchange membrane fuel cells[J]. Applied Surface Science, 2020, 504: 144096.

[25] BAO Z M, NIU Z Q, JIAO K. Numerical simulation for metal foam two-phase flow field of proton exchange membrane fuel cell[J]. International Journal of Hydrogen Energy, 2019, 44: 6229-6244.

[26] AZARAFZA A, ISMAIL M S, REZAKAZEMI M, et al. Comparative study of conventional and unconventional designs of cathode flow fields in PEM fuel cell[J]. Renewable and Sustainable Energy Reviews, 2019, 116: 109420 .

[27] AFSHARI E, HOUREH N B. Performance analysis of a membrane humidifier containing porous metal foam as flow distributor in a PEM fuel cell system[J]. Energy Conversion and Management, 2014, 88: 612-621.

[28] POURRAHMANI H, MOGHIMI M, SIAVASHI M, et al. Sensitivity analysis and performance evaluation of the PEMFC using wave-like porous ribs[J]. Applied Thermal Engineering, 2019, 150: 433-444.

[29] HAN S H, CHOI N H, CHOI Y D. Simulation and experimental analysis on the performance of PEM fuel cell by the wave-like surface design at the cathode channel[J]. International Journal of Hydrogen Energy, 2014, 39: 2628-2638.

[30] LI W K, ZHANG Q L, WANG C, et al. Experimental and numerical analysis of a three-dimensional flow field for PEMFCs[J]. Applied Energy, 2017， 195: 278-288.

[31] YANG Y T, TSAI K T, CHEN C K. The effects of the PEM fuel cell performance with the waved flow channels[J]. Journal of Applied Mathematics, 2013, 2013: 1-14.

[32] CHEN X, YU Z K, YANG C, et al. Performance investigation on a novel 3D wave flow channel design for PEMFC[J]. International Journal of Hydrogen Energy,
2021, 46(19): 11127-11139.

[33] YAN X H, GUAN C, ZHANG Y, et al. Flow field design with 3D geometry for proton exchange membrane fuel cells[J]. Applied Thermal Engineering, 2019, 147 : $1107-1114$.

[34] ANYANWU I S, HOU Y, XI F Q, et al. Comparative analysis of two-phase flow in sinusoidal channel of different geometric configurations with application to PEMFC[J]. International Journal of Hydrogen Energy, 2019, 44: 13807-13819.

[35] FAN L H, NIU Z Q, ZHANG G B, et al. Optimization design of the cathode flow channel for proton exchange membrane fuel cells[J]. Energy Conversion and Management, 2018, 171: 1813-1821.

[36] HENRIQUES T, CESAR B, BRANCO P. Increasing the efficiency of a portable PEM fuel cell by altering the cathode channel geometry: A numerical and experimental study[J]. Applied Energy, 2010，87: 1400-1409.

[37] GUVElioglu G H, STENGER H G. Flow rate and humidification effects on a PEM fuel cell performance and operation[J]. Journal of Power Sources, 2007, 163(2): 882-891.

[38] TROGADAS P, CHO J I S, NEVILLE T P, et al. A lung-inspired approach to scalable and robust fuel cell design[J]. Energy \& Environmental Science, 2018, 11: 136-143.

[39] GITTLEMAN C S, KONGKANAND A, MASTEN D, et al. Materials research and development focus areas for low cost automotive proton-exchange membrane fuel cells[J]. Current Opinion in Electrochemistry, 2019, 18: 81-89.

[40] SONG Y X, ZHANG C Z, LING C Y, et al. Review on current research of materials, fabrication and application for bipolar plate in proton exchange membrane fuel cell[J]. International Journal of Hydrogen Energy, 2020，45(54): 29832-29847.

[41] YIN Y, WANG X F, GUAN X S, et al. Numerical investigation on the characteristics of mass transport and performance of PEMFC with baffle plates installed in the flow channel[J]. International Journal of Hydrogen Energy, 2018, 43: 8048-8062.

[42] TING F P, HSIEH C W, WENG W H, et al. Effect of operational parameters on the performance of PEMFC assembled with $\mathrm{Au}$-coated $\mathrm{Ni}$-foam[J]. International Journal of Hydrogen Energy, 2012， 37: 13696-13703.

[43] LI S, SUNDEN B. Three-dimensional modeling and 
investigation of high temperature proton exchange membrane fuel cells with metal foams as flow distributor[J]. International Journal of Hydrogen Energy, 2017, 42: 27323-27333.

[44] CHEN H, GUO H, YE F, et al. An experimental study of cell performance and pressure drop of proton exchange membrane fuel cells with baffled flow channels[J]. Journal of Power Sources, 2020， 472: 228456.

[45] TOGHYANI S, NAFCHI F M, AFSHARI E, et al. Thermal and electrochemical performance analysis of a proton exchange membrane fuel cell under assembly pressure on gas diffusion layer[J]. International Journal of Hydrogen Energy, 2018，43: 4534-4545.

[46] 余鹏, 樊丽君, 杨永潮, 等. 基于超临界流体发泡技术 制备开孔型微孔塑料的研究进展 $[\mathrm{J}]$. 高分子材料科学 与工程, 2020, 36(10): 160-169.

YU Peng, FAN Lijun, YANG Yongchao, et al. Progress in preparation of open-cell microcellular plastics based on supercritical fluid foaming technology[J]. Polymer Materials Science \& Engineering, 2020, 36(10): 160-169.

[47] 王小峰, 蒋晶, 侯建华, 等. 化学物理联合微孔发泡成 型制备聚己内酯多孔材料[J]. 化工学报, 2014，65(6): 2386-2392.

WANG Xiaofeng, JIANG Jing, HOU Jianhua, et al. Fabrication of porous structure of poly( $\varepsilon$-caprolactone) via microcellular injection molding combined with chemical foaming[J]. CIESC Journal, 2014, 65(6): 2386-2392.

[48] SANTOS R V, GALlO M, JAEGER P, et al. New insights in the morphological characterization and modelling of poly( $\varepsilon$-caprolactone) bone scaffolds obtained by supercritical $\mathrm{CO}_{2}$ foaming[J]. The Journal of Supercritical Fluids, 2020, 166: 105012.

[49] MAHABUNPHACHAI S, CORA O N, KOC M. Effect of manufacturing processes on formability and surface topography of proton exchange membrane fuel cell metallic bipolar plates[J]. Journal of Power Sources,

2010, 195: 5269-5277.

[50] OSIA M B, HOSSEINIPOUR S J, BAKHSHI-JOOYBARI M. Forming metallic micro-feature bipolar plates for fuel cell using combined hydroforming and stamping processes[J]. Iranica Journal of Energy \& Environment, 2013, 4(2): 87-94.

[51] ZHANG B, LI Y T, BAI Q. Defect formation mechanisms in selective laser melting: A review[J].
Chinese Journal of Mechanical Engineering, 2017，30: 515-527.

[52] 刘伟, 李能, 周标, 等. 复杂结构与高性能材料增材制 造技术进展 [J]. 机械工程学报, 2019, 55(20): 128-151， 159.

LIU Wei, LI Neng, ZHOU Biao, et al. Progress in additive manufacturing on complex structures and high-performance materials[J]. Journal of Mechanical Engineering, 2019, 55(20): 128-151, 159.

[53] 朱胜. 柔性增材再制造技术 [J]. 机械工程学报, 2013, 49(23): $1-5$.

ZHU Sheng. Mobile additive remanufacturing[J]. Journal of Mechanical Engineering, 2013，49(23): 1-5.

[54] 李涤尘, 贺健康, 田小永, 等. 增材制造: 实现宏 微结构一体化制造[J]. 机械工程学报, 2013, 49(6): 129-135.

LI Dichen, HE Jiankang, TIAN Xiaoyong, et al. Additive manufacturing : Integrated fabrication of macro/ microstructures[J]. Journal of Mechanical Engineering, 2013, 49(6): $129-135$.

[55] 彭涁涁, 间献国, 杜娟. 基于 $\mathrm{BP}$ 和 $\mathrm{RBF}$ 神经网络的表 面质量预测研究[J]. 表面技术, 2020，49(10): 324-328, 337.

PENG Binbin, YAN Xianguo, DU Juan, et al. Surface quality prediction based on BP and RBF neural networks[J]. Surface Technology, 2020, 49(10): 324-328, 337.

[56] KOLIVUAO M, RAJESHKANAN A, JEEVANANTHAM A K. Study on computational and conventional method of determining volume of material removal in $\mathrm{CNC}$ milling process[J]. Materials Today: Proceedings, 2020, 22 : 1360-1368.

[57] 周伟, 刘阳旭, 褚旭阳, 等. 高孔率泡沫金属的孔结构 保形铣削加工研究 [J]. 机械工程学报, 2020, 56(1): 213-222.

ZHOU Wei, LIU Yangxu, CHU Xuyang, et al. Investigation of milling process of foam metal with high porosity for pore structure protection[J]. Journal of Mechanical Engineering, 2020， 56(1): 213-222.

[58] PORSTMANN S, WANNEMACHER T, DROSSEL W G. A comprehensive comparison of state-of-the-art manufacturing methods for fuel cell bipolar plates including anticipated future industry trends[J]. Journal of Manufacturing Processes, 2020, 60: 366-383.

[59] PENG L F, YI P Y, LAI X M. Design and manufacturing 
of stainless steel bipolar plates for proton exchange membrane fuel cells[J]. International Journal of Hydrogen Energy, 2014, 39(36): 21127-21153.

[60] 安华, 王喆, 王国锋, 等. 复合材料钻削表面粗粘度在 线监测与加工参数自适应优化 $[\mathrm{J}]$. 机械工程学报, 2020, 56(2): 27-34, 42.

AN Hua, WANG Zhe, WANG Guofeng, et al. Research on on-line monitoring of surface roughness in composite drilling and adaptive optimization of parameters[J]. Journal of Mechanical Engineering, 2020, 56(2): $27-34,42$

作者简介: 周伟(通信作者), 男, 1982 年出生, 教授, 博士研究生导师。 主要研究方向为精密制造技术、新能源与节能技术、智能微纳传感器。

E-mail: weizhou@xmu.edu.cn 